\title{
Genetic variability in the physiological responses of Andean lupin to drought stress
}

\author{
Clara Lizarazo, Frederick Stoddard, Pirjo Mäkelä and Arja Santanen
}

Department of Agricultural Sciences, PL 27 (Latokartanonkaari 5), 00014 University of Helsinki.

\begin{abstract}
Drought is one of the most important abiotic stresses that causes significant reductions in crop yield, and thus hinders the food security of the growing world population. In consequence, it is urgent to select crops able to resist drought, maintain high yield and have a good nutritive content. The purpose of this project was to evaluate the responses of different accessions of Andean lupin to drought stress, and identify if there are significant differences in their physiological responses.
\end{abstract}

To identify germplasm for further investigation, thirty accessions of Lupinus mutabilis Sweet. and one accession of L. albococcineus Hort. were screened in two sets, A of 15 and B of 16 accessions. From these sets, four lines were chosen on the basis of extreme values in the measurements, and this set of four was investigated in depth (set C). Water stress consisted of controlled water loss from the soil (at $2 \%$ per day). The screening techniques used were: leaf temperature, stomatal conductance, relative water content, water potential, ion membrane leakage, and shoot dry weight were measured and transpiration efficiency was calculated. In addition, carbon isotope discrimination, root length, root dry matter, proline content and soluble sugar content were included in only set $\mathrm{C}$.

Based on the results from set A and set B, accessions PI 457981, PI 457972, and AC 2792 were considered as being drought resistant and PI 510572 was considered as drought sensitive. However, the results from set $\mathrm{C}$ showed that accession PI 510572 is able to adapt its cell membrane to the drought stress so that its ion leakage is less than in the other accessions, and in addition it has the ability to accumulate higher concentrations of osmoprotectants.

Thus, this survey identified that some accessions of Andean lupin were able to avoid drought stress through stomatal traits and root traits, and others that were able to tolerate drought through the accumulation of osmotically active substances. Consequently, there are good prospects for breeding of Andean lupin to improve its drought resistance.

\section{Introduction}

During their life cycle, crops are constantly challenged by a wide range of biotic and abiotic stresses, among which drought is the single stress that causes the most severe yield losses and thus threatens world food security (Farooq et al. 2009). The influence of drought on plants can vary depending on its timing, duration and severity (Farooq et al. 2009). In general, the water deficits can cause many negative effects at the cell level such as: denaturation of proteins, disruption of membrane integrity, changes in solute concentration, accumulation of reactive oxygen species (ROS) and decreases in turgor pressure, which in turn cause adverse effects on crop physiology such as delays in developmental events, reductions in growth, reductions in photosynthetic activity and changes in the distribution and accumulation of assimilates, and as a result there can be severe yield losses (Mahajan \& Tuteja 2005, Farooq et al. 2009). In fact, yield reductions caused by drought can be up to 50\% or more depending on the crop species and growth stage (Wood 2005).

Drought has different impacts depending on the crop species, for example traditional staple foods like rice and maize are very sensitive to drought stress, and can have yield reductions as high as $80 \%$, and even cowpea, considered to be a drought resistant crop, can have yield reductions of about $50 \%$ (Sangakkara 2001, Farooq et al. 2009). Thus it has been suggested that for coping with the threats imposed by drought and climate change, it is necessary to switch agricultural systems to produce crops better adapted to the challenging environment and with a low demand for water (Brown \& Funk 2008, Cominelli et al. 2009). It is of utmost importance to develop new varieties of traditional crops to improve drought resistance;

furthermore, to achieve food security is also important to identify novel crops that might be better adapted to drought conditions.

Among all crops, legumes have been identified to have an important role to counteract climate change impacts on agricultural productivity and environmental wellbeing, due to their ability to biologically fix 
atmospheric nitrogen (Nösberger et al. 2000). In addition, legumes are highly appreciated for benefiting human health thanks to their role as the main vegetable source of protein (Nunes et al. 2008). Traditionally cultivated legumes, such as common beans, chickpea and soybean present considerable yield losses when exposed to drought stress (Farooq et al. 2009), thus it is necessary to consider the cultivation of alternative legume species, such as Lupinus mutabilis Sweet (Janick 2001, Jacobsen \& Mujica 2007).

The aim of this study was to evaluate the responses of different accessions of Andean lupin to drought stress, and to identify if there are significant differences in the physiological responses. In order to elucidate how Andean lupin responds to drought stress, the present study used different techniques to identify traits related to drought tolerance as well as drought avoidance.

\section{Materials and methods}

To identify germplasm with characteristics for drought resistance, thirty accessions of Lupinus mutabilis Sweet. and one accession of $L$. albococcineus Hort. were screened in two sets, A of 15 and B of 16 accessions. From each of these two sets, two lines were chosen on the basis of extreme values in the measurements, and this set of four was investigated in depth (set C). In all experiments, ten seeds of each chosen accession were sown in pots and grown in a glasshouse with $22^{\circ} \mathrm{C}, 18 \mathrm{~h}$ days and $18^{\circ} \mathrm{C}, 6 \mathrm{~h}$ nights, and were well watered until day 50 after planting. The pots were arranged in a randomized complete block design. The eight most uniform plants chosen were chosen, and four were exposed to water stress while watering of the other four was continued. Water stress consisted of controlled water loss from the soil, $20 \%$ water holding capacity at $2 \%$ per day over 9 days, so the soil reached $2 \%$ moisture content and was held at this level for 2 days. In all experiments, leaf temperature, stomatal conductance, relative water content, water potential, ion membrane leakage, and shoot dry weight were measured and transpiration efficiency was calculated. In set $\mathrm{C}$, carbon isotope discrimination, root length, root dry matter, proline content and soluble sugar content of the leaves were also determined.

\section{Results}

The analysis of set A and B revealed significant differences between treatments for all the parameters measured, except for relative water content, and there were also differences amongst accessions in certain parameters. PI 457972 and PI 457981 were selected for further investigation because of their low stomatal conductance under water stress conditions and low water use, and PI 510572 was selected as sensitive to drought stress due to its high water use, ion membrane leakage and water potential under water stress conditions. In addition AC 2792 (L. albococcineus) was selected due to its low stomatal conductance and water use, and high leaf temperature under water stress conditions.

In the final experiment, PI 457981 and PI 457972 appeared to avoid drought through appropriate stomatal characteristics. PI 457981 showed low stomatal conductance, high leaf temperature and also high root length; similarly, accession PI 457972 showed low water potential, low stomatal conductance, low carbon isotope discrimination and accumulation of soluble sugars. Accession PI 510572 contrasted for these stomatal traits, but interestingly it showed low membrane ion leakage, high proline content and soluble sugars content, suggesting that it was capable of drought tolerance by osmotic adjustment. Finally, accession AC2792 showed low water use, low water potential and low carbon isotope discrimination. In summary, there were some traits that had the same pattern among all accessions while other traits had a particular trend depending on the genotype (Table 1). 
Table 1. Summary of the physiological traits of four Andean lupin accessions, arrows indicate the variation of the response from the well watered to the water stress treatment. $(\uparrow=$ increased, $\downarrow=$ decreased $)$.

\begin{tabular}{|l|l|l|l|l|}
\hline & \multicolumn{4}{|c|}{ Accessions } \\
\hline Parameter & PI 510572 & PI 457972 & PI 457981 & AC 2792 \\
\hline Water potential & $\downarrow$ & $\downarrow$ & $\downarrow$ & $\downarrow$ \\
\hline Stomatal conductance & $\downarrow$ & $\downarrow$ & $\downarrow$ & $\downarrow$ \\
\hline Leaf temperature & $\uparrow$ & $\uparrow$ & $\uparrow$ & $\uparrow$ \\
\hline Carbon isotope discrimination & $\downarrow$ & $\downarrow$ & $\downarrow$ & $\downarrow$ \\
\hline Transpiration efficiency & $\uparrow$ & $\uparrow$ & $\uparrow$ & $\uparrow$ \\
\hline Ion membrane leakage & $\downarrow$ & $\uparrow$ & $\uparrow$ & $\uparrow$ \\
\hline Soluble sugars content & $\uparrow$ & $\uparrow$ & $\uparrow$ & $\uparrow$ \\
\hline Proline content & $\uparrow$ & $\uparrow$ & $\uparrow$ & $\uparrow$ \\
\hline Shoot dry weight & $\downarrow$ & $\downarrow$ & $\downarrow$ & $\downarrow$ \\
\hline Root length & $\uparrow$ & $\downarrow$ & $\downarrow$ & $\downarrow$ \\
\hline Root dry weight & $\downarrow$ & $\uparrow$ & $\downarrow$ & $\downarrow$ \\
\hline Leaf dry matter content & $\uparrow$ & $\downarrow$ & $\uparrow$ & $\downarrow$ \\
\hline
\end{tabular}

\section{Discussion}

After the induction of water stress, plants under the two treatments started to show marked differences in their physiological functioning depending on the water availability; overall in both set A and B, the water stress treatment caused significant decreases in the water potential and stomatal conductance, while leaf temperature increased, so it is clear that the water deficit was sufficiently severe. The analyses of variance revealed that there were significant differences amongst accessions in some parameters but not in both treatments nor in both sets.

The results from Set C agree with those of Set A and Set B, as stomatal conductance decreased and leaf temperature increased in all accessions with water stress, furthermore in both parameters the treatment $\mathrm{x}$ accession interaction was significant. These results confirm that stomatal adjustment is a common response to water stress in all the accessions, but some can use it more efficiently than others. On the other hand, the ranking of accessions according to stomatal conductance was different between sets. This might be associated with various environmental influences and reveals the difficulty to reproduce the exact same conditions across experiments of drought stress; a similar situation has been reported in soybean studies (James et al. 2008a). Nevertheless, stomatal conductance can be a useful trait for selecting drought resistant Andean lupins, as it has been used in many other legumes such as soybean (James et al. 2008a), cowpea (Anyia, Herzog 2004), lentil (Shrestha et al. 2006) faba bean (Khan et al. 2007) and common bean (Cruz de Carvalho et al. 1998).

The screening techniques used in set $\mathrm{C}$ allowed identifying interesting trends in ion membrane leakage, accumulation of osmoprotectants and root characteristics. Accession PI 510572 had the lowest proline and soluble sugar content in the well watered treatment; moreover it had the highest proline and soluble sugar content in the water stress treatment. Accessions PI 457981 and PI 457982 had similar levels of osmoprotectants, while accession AC 2792 had almost no difference in soluble sugar content between the two treatments. Although the differences in content of osmoprotectants amongst accessions were not significant, the analysis of variance shows that they were very close to reach significance. Moreover, the probability of the treatment $\mathrm{x}$ accession interaction for soluble sugars was 0.154 and for proline 0.108 , suggesting that more replication might have allowed the experiment to detect significance. In addition, several accessions in Set A and B, and accession PI 510572 had higher ion leakage in the well watered treatment than in the water stress treatment, this might indicate that Andean lupin can adapt its cell membrane during periods of water stress, but that ability is dependent on the genotype.

The results of the present study about ion membrane leakage, soluble sugars and proline content reveal interesting variations in the way different Andean lupin accessions use the strategies of drought tolerance, thus it will be worthwhile to do further investigation of those traits. 
In addition, accession PI 457972 was the only one that showed higher root dry weight under water stress than in well watered conditions, and this might suggest that in this accession water stress triggers an increase in root growth. Increases in root weight can be associated with root proliferation or root length; as this accession did not show an increase in root length between treatments, the increase in root weight may be attributed to increase in root density by means of proliferation of lateral roots. Previous studies in $L$. mutabilis cv. Potosi reported decreases in root weight of about $10 \%$ from well watered conditions to water stress conditions (Carvalho et al. 2004). Furthermore, increases in root weight in response to water stress have been reported only in rare cases (Blum 1996); thus, the increase in root weight in accession PI 457972 in response to water stress is worth examining further. Increased root length, density and biomass are primary traits of drought avoidance and allow more water extraction from deeper soil layers, which has shown a positive effect on seed yield under water stress conditions in studies on crops like sorghum and chickpea (Serraj et al. 2004, Kashiwagi et al. 2005, Mahajan \& Tuteja 2005, Kashiwagi et al. 2008, Khan et al. 2009); therefore it can be said that accession PI 457972 has an advantageous root system and thus it can be a promising material in breeding programs to improve Andean lupin for drought stress conditions.

Combining the information gathered from the different screening techniques, it becomes evident that Andean lupin accessions have some similarities in drought avoidance and tolerance strategies but also differ in some of them. Such differences might be due to the constitutive nature of some traits and to the interactions between genotype and treatment in other traits. Furthermore, their different geographic provenance implies some differences in the environmental conditions in which each accession was developed and this might have allowed some degree of diversification in the physiological responses of Andean lupins to water stress.

\section{References}

Anyia, A.O. \& Herzog, H. 2004. Water-use efficiency, leaf area and leaf gas exchange of cowpeas under mid-season drought. European Journal of Agronomy 20: 327-339.

Blum, A. 2005. Drought resistance, water-use efficiency, and yield potential - are they compatible, dissonant, or mutually exclusive? Australian Journal of Agricultural Research 56: 1159-1168.

Blum, A. 1996. Crop responses to drought and the interpretation of adaptation. Plant Growth Regulation 20: $135-148$.

Brown, M.E. \& Funk, C.C. 2008. Food security under climate change. Science 319: 580-581.

Carvalho, I., Ricardo, C. \& Chaves, M. 2004. Quality and distribution of assimilates within the whole plant of lupines (L. albus and L. mutabilis) influenced by water stress. Journal of Agronomy and Crop Science 190: $205-210$.

Cominelli, E., Galbiati, M., Tonelli, C. \& Bowler, C. 2009. Water: the invisible problem. EMBO reports 10: 671- 676.

Cruz de Carvalho, M.H., Laffray, D. \& Louguet, P. 1998. Comparison of the physiological responses of Phaseolus vulgaris and Vigna unguiculata cultivars when submitted to drought conditions. Environmental and Experimental Botany 40: 197-207.

Farooq, M., Wahid, A., Kobayashi, N., Fujita, D. \& Basra, S.M.A. 2009. Plant drought stress: effects, mechanisms and management. Agronomy for Sustainable Development 29: 185-212.

Jacobsen, S.E. \& Mujica, A. 2007. Geographical distribution of the Andean lupin (Lupinus mutabilis). In: Ochatt, S. \& Jain, S.M. (eds.) Breeding of neglected and under-utilized crops, spices and herbs. New Hampshire, USA: Science Publishers. pp. 95-107.

James, A.T., Lawn, R.J. \& Cooper, M. 2008a. Genotypic variation for drought stress response traits in soybean. I. Variation in soybean and wild Glycine spp. for epidermal conductance, osmotic potential, and relative water content. Australian Journal of Agricultural Research 59: 656-669.

Janick, J. 2001. New crops for the 21st century. In: Nösberger, J., Geiger, H. \& Struik, P.C. (eds.). Crop science: progress and prospects. Wallingford, U.K: CABI Publishing. pp. 307-327.

Kashiwagi, J., Krishnamurthy, L., Upadhyaya, H., Krishna, H., Chandra, S., Vadez, V. \& Serraj, R. 2005. Genetic variability of drought-avoidance root traits in the mini-core germplasm collection of chickpea (Cicer arietinum L.). Euphytica 146: 213- 222. 
Kashiwagi, J., Krishnamurthy, L., Gaur, P.M., Chandra, S. \& Upadhyaya, H.D. 2008. Estimation of gene effects of the drought avoidance root characteristics in chickpea (C. arietinum L.). Field Crops Research 105: 64-69.

Khan, H.u., Link, W., Hocking, T. \& Stoddard, F. 2007. Evaluation of physiological traits for improving drought tolerance in faba bean (Vicia faba L.). Plant and Soil 292: 205-217.

Khan, H.R., Paull, J.G., Siddique, K.H.M. \& Stoddard, F.L. 2009. Faba bean breeding for drought-affected environments: A physiological and agronomic perspective. Field Crops Research. In Press, Corrected Proof.

Mahajan, S. \& Tuteja, N. 2005. Cold, salinity and drought stresses: An overview. Archives of Biochemistry and Biophysics 444: 139-158.

Nösberger, J., Blum, H. \& Fuhrer, J. 2000. Crop ecosystem responses to climatic change: productive grasslands. In: Reddy, K.R. \& Hodges, H.F. (eds.) Climate change and global crop productivity. Wallingford, U.K: CABI Publishing. pp. 271-291.

Nunes, C., de Sousa Araújo, S., da Silva, J.M., Fevereiro, M.P.S. \& da Silva, A.B. 2008. Physiological responses of the legume model Medicago truncatula cv. Jemalong to water deficit. Environmental and Experimental Botany 63: 289-296.

Sangakkara, U.R. 2001. Plant stress factors: their impact on productivity of cropping systems. In: Nösberger, J., Geiger, H. \& Struik, P.C. (eds.). Crop science: progress and prospects. Wallingford, U.K: CABI Publishing. pp. 101-117.

Serraj, R., Krishnamurthy, L., Kashiwagi, J., Kumar, J., Chandra, S. \& Crouch, J.H. 2004. Variation in root traits of chickpea (Cicer arietinum L.) grown under terminal drought. Field Crops Research: 115-127.

Shrestha, R., Turner, N.C., Siddique, K.H.M. \& Turner, D.W. 2006. Physiological and seed yield responses to water deficits among lentil genotypes from diverse origins. Australian Journal of Agricultural Research 57: 903-915.

Wood, A.J. 2005. Eco-physiological adaptations to limited water environments in Plant abiotic stress. In: Jenks, M.A. \& Hasegawa, P.M. (eds.) Plant abiotic stress. Oxford, UK: Blackwell Publishing, pp. 1-13. 